\title{
MODIFICATION OF THE GAS OUTLET STRUCTURE ON THE SPOUTED BED WITH INNER DRAFT-TUBE
}

\author{
Hirotsugu HATTORI, ATSUro KOBAYASHI, IWAo AIBA AND TETSUYA KODA \\ Department of Chemical Engineering, Shinshu University, Ueda 386
}

Key Words: Chemical Reactor, Spouted Bed, Modification, Draft Tube, Gas Outlet

The side-outlet spouted bed with inner draft-tube has many advantageous characteristics. One of them is that all of the gas percolates through the annular dense bed and such a flow pattern of gas gives high efficiency of gas-solid contact. The side-outlet spouted bed with inner draft-tube provides high gas conversions in the first-order solid-catalyzed reaction. ${ }^{4)}$ Another is the possibility of the use of relatively fine solid particles. ${ }^{1)}$ However, the side-outlet spouted bed with inner draft-tube also has some disadvantageous characteristics. The most serious one lies in the structure of the gas outlet. Fine screens are usually put on the gas outlet openings of the side-outlet spouted beds previously proposed. ${ }^{2-4)}$ Such a structure of the gas outlet causes plugging of solid particles when fine particles or friable particles are spouted. This is an important problem and should be solved in order to apply the side-outlet spouted bed with inner drafttube to industrial operations.

We proposed in the previous paper a different gas outlet structure to avoid the plugging of solid particles. ${ }^{1)}$ A stationary solid bed was attached outside the gas outlet openings. In this structure, there is no screen on the gas outlet openings and therefore plugging does not occur. However, the attachment of a stationary solid bed is not necessarily a desirable method. The reason is as follows. The most important characteristic of the spouted bed is that all the particles always move within the apparatus, and the attachment of the stationary solid bed removes this characteristic from the modified spouted bed. From this point of view we have again attempted to modify the structure of the gas outlet and have invented a new one.

In this paper the new structure of the gas outlet of the spouted bed is proposed. This structure requires the attachment of neither screen nor stationary solid bed on the gas outlet openings. All the particles circulate within the apparatus.

Received February 16, 1983. Correspondence concerning this article should be addressed to $\mathrm{H}$. Hattori.

\section{A New Structure of Gas Outlet}

The modified structure of the gas outlet is shown in Fig. 1. As can be seen therein, the column wall is separated into two parts: the upper column and the lower one. The diameter of the lower column is larger than that of the upper column, and there is a slight overlap between the two columns.

If the solid particles are poured into this apparatus and a sufficient amount of gas is fed, spouting behavior begins. The spout is formed in the inner drafttube and an annular bed is formed in the surroundings of the spout. In this structure, two stages of the bed surface appear at the top of the annular bed as shown in Fig. 1. The upper surface is formed around the top of the inner draft-tube and the lower surface is formed around the lower end of the upper column. The gas goes out from the lower surface on which no screen is attached, as shown in Fig. 1.

The motion of solid particles is also shown in Fig. 1. They are carried upward in the inner draft-tube and fall onto the above-mentioned upper surface. Then they move slowly downward in the annular bed. It is observed that the solid particles flow radially from the inside of the upper column wall to the bed surface of the lower column, passing through the part just below the end of the upper column. After reaching the lower surface, these particles move downward along the lower column wall, receiving a frictional force caused by the particles moving through the inner part of the bed. The amount of particles reaching the lower surface is always the same as that of particles leaving the same surface. Therefore, the lower surface of the annular bed is kept at a constant level.

Figure 2 shows the pressure distribution and the gas streamlines in the annular bed. The gas streamlines are drawn in such a way that the volumetric flow rate of the gas passing through each stream tube between two adjacent streamlines is one-tenth of all the gas percolating through the annulus. No undesirable characteristics can be found in the gas flow pattern. These results were obtained by using spherical glass particles of $1.8 \mathrm{~mm}$ average diameter and air at room 


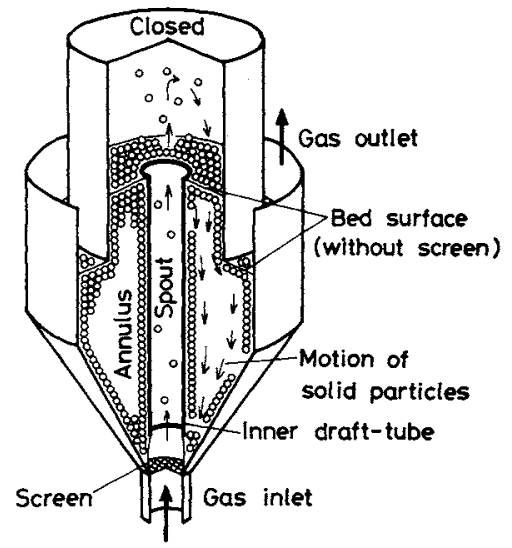

Fig. 1. Modified structure of gas outlet.

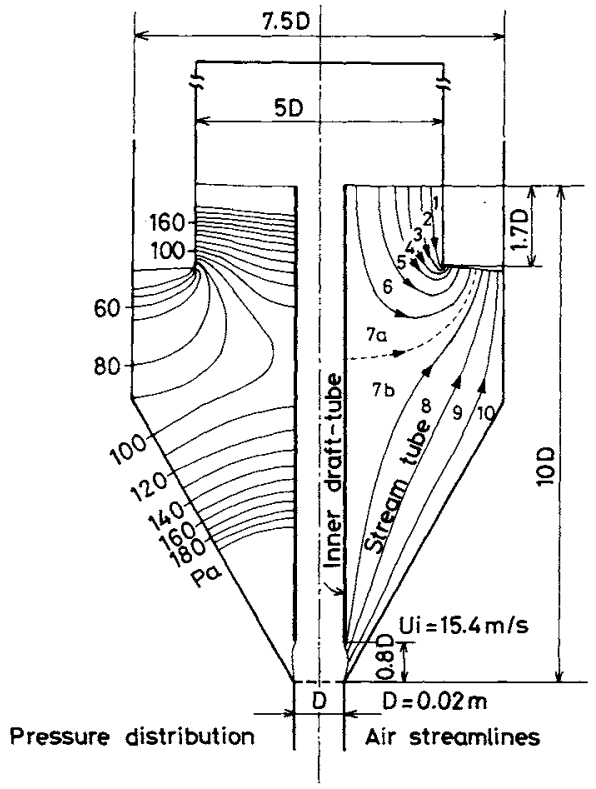

Fig. 2. Pressure distribution and air streamlines in annular bed.

temperature. Physical properties of these particles are shown in Table 1.
Table 1. Physical properties of solid particles

Glass beads (specific gravity $=2.5$ )

\begin{tabular}{ccc} 
Tyler mesh & $\begin{array}{c}\text { Average diameter } \\
{[\mathrm{mm}]}\end{array}$ & $\begin{array}{c}\text { Terminal velocity } \\
{[\mathrm{m} / \mathrm{s}]}\end{array}$ \\
\hline$-9+10$ & 1.8 & 10.5 \\
\hline
\end{tabular}

\section{Conclusion}

A modified structure of the gas outlet of the spouted bed with inner draft-tube was developed and the gas streamlines in the bed were measured. The new structure requires the attachment of neither screen nor stationary solid bed on the gas outlet openings. It was found that the problem of the plugging of solid particles can be avoided without preventing circulation of the particles in the vessel.

\section{Acknowledgment}

We would like to express our thanks to Dr. Takashi Shirai of Tokyo Science University for his helpful suggestions. We are grateful to Dr. Taiichi Shibuya and Dr. Hideomi Matsuda of Shinshu University for helpful discussions and for reading the manuscript.

\section{Nomenclature}

$D=$ gas inlet diameter [m]

$U_{i} \quad=$ average gas velocity at gas inlet $\quad[\mathrm{m} / \mathrm{s}]$

\section{Literature Cited}

1) Hattori, H. and K. Takeda: J. Chem. Eng. Japan, 11, 125 (1978).

2) Hattori, H., K. Tanaka and K. Takeda: J. Chem. Eng. Japan, 14, 462 (1981).

3) Takeda, K. and H. Hattori: Kagaku Kogaku Ronbunshu, 1, 149 (1975).

4) Takeda, K. and H. Hattori: Kagaku Kogaku Ronbunshu, 2, 507 (1976). 